\title{
Os sentidos atribuídos à queixa escolar por profissionais de escolas públicas municipais
}

\author{
Lucas Schweitzer ${ }^{1} ;$ https://orcid.org/0000-0003-4421-8709
}

Simone Vieira de Souza'; https://orcid.org/0000-0003-4977-8879

\begin{abstract}
Resumo
A queixa escolar é um fenômeno central no contexto educacional, sendo crescente o número de encaminhamentos aos Serviços de Psicologia por conta deste fenômeno. O objetivo desta pesquisa foi compreender os sentidos atribuídos por profissionais de escolas públicas acerca da queixa escolar, com ênfase aos motivos atribuídos e às estratégias utilizadas por professores e escolas, no atendimento aos estudantes com queixa escolar. Para buscar essa compreensão, foram entrevistados professores, diretores e assistentes técnico-pedagógicos de escolas públicas municipais de um município da Grande Florianópolis. Os resultados indicaram uma atribuição de culpabilidade aos próprios estudantes e a suas famílias em relação às queixas escolares. As principais estratégias de atendimento tanto das escolas quanto dos professores centraramse na própria criança e isentaram, na maioria das vezes, a escola da produção da queixa escolar. Também se destacou a presença de discursos que naturalizam práticas que estigmatizam estudantes com dificuldades no processo de escolarização.
\end{abstract}

Palavras-Chave: Psicologia escolar; fracasso escolar; interação professor-aluno.

\section{The meanings professionals of municipal public schools attribute to complaints against school conduct}

\begin{abstract}
Complaints against school conduct is a central phenomenon in the educational context, and, because of that, the number of referrals to the Psychology Services is increasing. This research aimed to understand the meanings attributed by public school professionals about complaints regarding school misconduct, with emphasis on the reasons attributed and the strategies used by teachers and schools in the care of students who present a complaint against school conduct. To understand that, teachers, principals and technical-pedagogical assistants from municipal public schools of a municipality of Metropolitan Florianópolis were interviewed. The results indicated that the students themselves and their families were considered guilty for school misconduct. The main care strategies from both schools and teachers have focused on the child itself and have mostly exempted school from causing that discomfort. The presence of speeches that naturalize practices stigmatizing students with difficulties in the schooling process was also highlighted.
\end{abstract}

Keywords: School Psicology; school failure; teacher student interaction.

\section{Los sentidos atribuidos a la queja escolar por profesionales de escuelas públicas municipales}

\begin{abstract}
Resumen
La queja escolar es un fenómeno central en el contexto educacional, siendo creciente el número de encaminamientos a los Servicios de Psicología por cuenta de este fenómeno. El objetivo de esta investigación fue comprender los sentidos atribuidos por profesionales de escuelas públicas acerca de la queja escolar, con énfasis a los motivos atribuidos y las estrategias utilizadas por profesores y escuelas, en la atención a los estudiantes con queja escolar. Para buscar esa comprensión, se entrevistaron a profesores, directores y asistentes técnico-pedagógicos de escuelas públicas municipales de un municipio de la Gran Florianópolis. Los resultados indicaron una atribución de culpabilidad a los propios estudiantes y a sus familias en relación a las quejas escolares. Las principales estrategias de atención de las escuelas y de los profesores se centraron en el propio niño y eximen, en la mayoría de las veces, la escuela de la producción de la queja escolar. También se destacó la presencia de discursos que naturalizan prácticas que estigmatizan estudiantes con dificultades en el proceso de escolarización.
\end{abstract}

Palabras clave: Psicología Escolar; fracaso escolar; interacción profesor-estudiante.

1 Universidade Federal de Santa Catarina - Florianópolis - SC - Brasil; lucass.schweitzer@gmail.com; sivieira@hotmail.com 


\section{Introdução}

O presente estudo tem o objetivo de compreender os sentidos atribuídos por profissionais de escolas públicas municipais acerca da queixa escolar. A queixa escolar é relacionada às dificuldades no processo de escolarização, que originam encaminhamentos de avaliação psicológica ou atendimento individual. Trata-se de um tema que emerge de uma rede de relações que tem como personagens principais o estudante, sua escola e sua família. O cenário principal em que a queixa escolar surge e é sustentada é o universo escolar(Souza, 2007; Souza, 2013; Oliveira, Bragagnolo, \& Souza, 2014).

Para compreender a complexidade deste fenômeno, é preciso considerar os diversos sujeitos envolvidos em sua produção, mas que, historicamente, não foram incluídos nessa discussão, configurando-se num processo que desconsidera a produção multifacetada daquilo que emerge como um problema supostamente individualizado no estudante(Souza, 2007).

Ao estabelecer uma relação entre questões de saúde e fracasso escolar, Moysés (1990) afirma que a criança que está na escola não é uma criança doente em si mesma, com causas e consequências em seu próprio organismo. Ela sofre as consequências de condições agressivas sob qualquer ângulo que se analisa sua vida. Por não existirem causas médicas reais para o fracasso escolar, observa-se uma construção artificial dessas causas, com a construção de falsas relações entre «doença" e "não-aprendizagem", centradas no indivíduo (Moysés, 1990).

A queixa escolar não pode ser compreendida, exclusivamente, a partir da própria criança, sem o devido contato com os outros envolvidos nessa queixa. Diversos estudos trazem discussões críticas em relação às explicações biologicistas para a queixa escolar e sobre o processo de naturalização criado em torno deste fenômeno (Asbahr, Martins, \& Mazzolini, 2011; Bray \& Leonardo, 2011; Asbahr \& Nascimento, 2013). Apesar dessas discussões, verifica-se um crescente número de encaminhamentos para os serviços de Psicologia, com queixas relacionadas ao contexto escolar (Rodrigues, Campos, \& Fernandes, 2012) que, por vezes, partem de uma lógica monocausal.

Patto (1990) questiona as explicações sobre as causas para as dificuldades de aprendizagem escolar, centradas nas características psicossociais do aprendiz, fazendo refletir sobre a lógica de patologização da queixa escolar. Ressalta-se a necessidade de se problematizara compreensão da queixa escolar não como reflexo de problemas emocionais, cognitivos ou comportamentais do estudante; mas, pelo contrário, como um produto das relações escolares. Há necessidade de se rever o processo diagnóstico e seus instrumentos de avaliação, sob pena de se instituírem destinos que distanciam o indivíduo de sua condição de ser humano de direitos (Souza, 2009).

Pensar o ambiente escolar é ser coerente com a concepção de que o sujeito se estrutura na relação com o outro, já que essa relação oferece elementos para que se possa in- vestigar, compreender e atuar junto aos diversos envolvidos na produção e na manutenção das queixas escolares. Essa concepção vai de encontro ao que as pesquisas sobre as causas da queixa escolar, tradicionalmente, tiveram como foco: as características dos estudantes e de seu meio familiar. Vale destacar que, além desses meios, existe a escola que, como tal, é campo de contradições e paradoxos. Nela atuam forças que tendem a produzir fracasso e sofrimento nas pessoas que dela fazem parte, com estratégias de homogeneização, faltas e trocas de professores, pedagogia repetitiva, entre outros (Souza, 2007).

Ao analisar o sentido produzido pela queixa escolar nas crianças em processo de escolarização, Souza (2013) parte do pressuposto de que o processo de constituição humana se dá por meio de mediações. A criança, assim, é afetada por essas experiências, as quais se configuram como restritivas ou emancipadoras do seu desenvolvimento. O estudo demonstrou ainda que as sucessivas experiências de humilhação, repetência, exclusão e medicalização produzem sofrimento e atribuição de sentidos negativos às histórias de pouco sucesso escolar, além de destacar o peso do olhar desqualificador sobre os estudantes, quando prevalece a lógica da normatização na escola (Souza, 2013).

Outra questão importante refere-se à profecia autorrealizadora (Rosenthal \& Jacobson, 1981), segundo a qual, quando uma criança dentro da escola demonstra alguma dificuldade diante de uma tarefa, ou por outro meio, é "etiquetada" como estudante com dificuldades de aprendizagem. Isso vem ocorrendo cada vez com maior frequência, sendo que o que seria uma suspeita de dificuldade do processo de ensino e aprendizagem dá origem a uma profecia autorrealizadora. A partir desses fatos, as dificuldades experienciadas pelo estudante configuram-se como situação de fracasso, sendo que, ao não conseguir êxito nas exigências escolares, ele imerge em sentimentos de frustração que podem culminar no abandono da escola (Patto, 1990; Souza, 2013).

A reflexão aqui proposta diz respeito ao papel do professor e da escola na produção da queixa escolar. Ao não encontrar um "bode expiatório", entende-se a complexidade do fenômeno, sem buscar respostas isoladas para a compreensão do processo. Posto isso, objetivou-se, com este estudo, compreender os sentidos atribuídos à queixa escolar por profissionais de escolas públicas municipais do ensino fundamental de uma cidade da Grande Florianópolis. Assim, buscou-se conhecer os motivos atribuídos à produção da queixa escolar, bem com identificar as estratégias utilizadas por professores e caracterizar os procedimentos de escolas frente ao tema.

\section{Método}

Esta pesquisa pode ser definida como de abordagem qualitativa, e tem por objetivo captar o fenômeno em estudo a partir da perspectiva das pessoas envolvidas, considerando os depoimentos relevantes com vistas ao entendimento da dinâmica do fenômeno (Godoy, 1995). O delineamento é 
de estudo de caso, com profundo e exaustivo estudo de um ou alguns objetos, com vistas ao amplo e detalhado conhecimento acerca do assunto (Gil, 2002).

Em relação aos instrumentos de coleta, foram utilizadas duas entrevistas semiestruturadas individuais, uma com foco nos professores e outra para os diretores e assistentes técnico-pedagógicos. A coleta de dados foi realizada em salas das escolas e as respostas foram registradas em um gravador de voz.

Considera-se que o contato com os participantes teve início na Secretaria Municipal de Educação, onde foram obtidas informações sobre as escolas públicas municipais de uma cidade da região da Grande Florianópolis, previamente definida, e foi concedida autorização para as entrevistas nas escolas. Feito isso, foram realizados contatos pessoais com os diretores das escolas, avaliando a possibilidade de realização da pesquisa e efetivou-se a assinatura do Termo de Ciência e Acordo entre as Instituições. O projeto de pesquisa foi submetido à aprovação do Comitê de Ética em Pesquisa (Parecer CEP/Unisul: 796.611) e, a partir de então, foram agendadas as entrevistas, conforme disponibilidade dos profissionais das escolas.

Para a seleção dos participantes, foram contatadas as três escolas públicas municipais com o maior número de matrículas. Foram entrevistados um(a) professor(a), um(a) diretor ou um(a) assistente de direção e um(a) Assistente Técnico-Pedagógico(a) (ATP) de cada escola, indicados pelas próprias escolas, com base na disponibilidade dos profissionais. Contudo, alguns critérios foram observados para a inclusão desses professores na pesquisa, sendo: estar vinculado a uma ou mais turmas do ensino fundamental; ter acima de 18 anos de idade; e possuir, no mínimo, dois anos de experiência na atividade docente. Para os demais participantes, exigia-se ter acima de 18 anos e dois anos de experiência na área da educação.

Para a análise dos dados colhidos, foi realizada uma análise de conteúdo, definida por Chizzotti (2001) como um procedimento com o objetivo de compreender criticamente o sentido das comunicações. As informações foram organizadas em categorias definidas a posteriori, pois pesquisas de estudo de caso tendem a produzir um grande número de categorias relevantes (Yin, 2001).

No capítulo de análise, os dados foram organizados em três subcapítulos, um para cada escola. Foram discutidos três eixos: motivos atribuídos à queixa escolar; estratégias para o atendimento a casos de queixa escolar e; procedimentos das escolas para o atendimento a queixa escolar.

\section{Resultados e Discussão}

Neste item, os casos das três escolas são apresentados, separadamente, devido às especificidades de cada uma delas.

\section{Escola 1}

A escola 1, conforme referido na metodologia, faz parte da rede municipal de ensino fundamental do município selecionado para este estudo, e conta com cerca de 400 estudantes.Questionadas sobre os motivos para a existência de queixas escolares, a diretora atribuiu-a "à falta de tempo dos pais para com os seus filhos"; e a professora apontou, como razão, o fato de que "os pais são separados". Essas falas vão ao encontro do que Patto (1990) já debatia, isto é, que as versões para descrever o fracasso escolar mantêm em comum a explicação de que a causa da dificuldade ou é do estudante ou da sua família. Ao desconsiderar mecanismos que criam e cronificam as experiências de fracasso, vividas pelo estudante e por sua família, essas versões colocam-se a serviço da reiteração de uma crença de incompetência por parte dos estudantes e de seu contexto familiar (Patto, 1990).

Além do envolvimento da família, a professora afirmou haver relação da queixa escolar com aspectos da própria criança, como a "preguiça mesmo"; e aspectos de ordem inata: "eu acho que já vem da criança". Esses aspectos podem ser confrontados com base em Rego (1997), que considera que as características tipicamente humanas não são inatas, nem são meros resultados de pressões do meio externo. Elas resultam da interação dialética do homem e seu meio sociocultural (Rego, 1997). Ao atribuir à criança a responsabilidade por seu "fracasso", exime-se todo um contexto de relações que está implicado nesse processo de não aprendizado ou de problemas de comportamento.

Outro dado relevante da fala da professora remete a quando ela assim pontuou: "acho impossível uma criança não falar em sala de aula, né? Ficar quieto como a gente sempre deseja que seja, ali, escutando a gente, ouvindo a gente e obedecendo. Isso eu acho que nunca vai acontecer". Essa fala pode expressar um possível desejo de que as crianças fiquem em silêncio "recebendo" o conhecimento e obedecendo. Esse desejo, contudo, contraria a própria necessidade de interação da criança com o meio social, visto que, é por meio das mediações que haverá aprendizagem e desenvolvimento. Há diversos registros de que o comportamento desviante do esperado, oposto ao silêncio e à obediência em sala, tem sido "patologizado" pelos professores (Souza, 2000; Souza, 2007). A fala da professora remete, ainda, a uma discussão evidenciada por Bray e Leonardo (2011), questionando o papel de aprendizagem passiva atribuída ao estudante.

Quanto às estratégias utilizadas pelos professores para o atendimento a casos de queixa escolar, o encaminhamento dos estudantes com problemas de comportamento para a direção apresentou-se com freqüência no relato dos entrevistados: "eles vêm parar aqui, eu também não sei se é porque [os professores] estão esgotados, estão cansados" (diretora); "a gente conversa primeiro com o aluno. Se, caso não resolver, a gente, né, conversa com a direção, passa a situação para a direção" (professora). 
Os profissionais também citaram a utilização de estratégias diferenciadas de ensino para estudantes com dificuldades de aprendizagem: "levava várias atividades coordenadas para que ele se acalmasse" (ATP); "a gente tenta fazer de outras formas, dá outras atividades" (Diretora). Percebe-se que, apesar de tais estratégias ainda indicarem certo desconhecimento da gênese multifacetada do problema, elas demonstram um esforço na busca por alternativas que propiciem aproximar-se dos estudantes. Por meio das estratégias lúdicas, demonstra-se certo cuidado com eles, com respeito aos seus potenciais e a sua criatividade.

No que diz respeito aos procedimentos utilizados pela escola no atendimento de casos de queixa escolar, a diretora afirmou: "sempre que acontece de esses professores virem até nós, e nós não conseguimos resolver com os pais, nós indicamos os órgãos competentes", e revelou a existência de um caderno para anotações das "falhas" dos estudantes. A professora, por sua vez,sobre os procedimentos, disse:"caso a gente vê, né, algum problema muito mais sério, aí a gente chama alguém da Secretaria [da Educação]"; já a ATP destacou a importância do trabalho de reforço escolar e à existência de um projeto para atendimento a casos de dificuldade de aprendizagem.

Percebe-se, assim, que esses procedimentos dizem respeito ao atendimento dos estudantes e ao encaminhamento para outros serviços especializados. Não são, na verdade, apresentadas propostas de mudanças da escola ou dos professores para o atendimento aos casos. Essas falas corroboram com Moysés e Collares (1997), sobre que a instituição escolar é reconhecida como praticamente isenta de responsabilidades quanto ao fracasso escolar de seus alunos. Assim, ao sistema escolar acaba por ser atribuída a noção de plano secundário, ao se referir às causas desse fracasso.

\section{Escola 2}

Do mesmo modo, a escola 2 faz parte da rede municipal de ensino de uma cidade da Grande Florianópolis, é dedicada exclusivamente ao ensino fundamental e conta com cerca de mil estudantes. Quanto aos motivos atribuídos à queixa escolar, os discursos dos profissionais desta escola foram relacionados e dirigidos à responsabilização da família: "às vezes, são crianças que vêm de famílias desestruturadas" (assistente de direção); "eu acho que 50\% não têm estrutura familiar; as famílias hoje em dia são muito ausentes da escola, não existe cobrança" (professor). Essas atribuições podem ser relacionadas com o que afirma Asbahr e Lopes (2006) sobre a visão historicamente preconceituosa, segundo a qual os estudantes não aprendem porque sua constituição familiar não é favorável ao bom desenvolvimento psíquico e ao sucesso escolar (Asbahr \& Lopes, 2006).

Os profissionais também mencionaram um modelo de família tradicional e triangular, composto por pai-mãe-filho, enquanto que, cada vez mais, na contemporaneidade, a configuração familiar tem apresentado diversos modelos. Cabe destacar a necessidade de quebra com um modelo tradicional que, talvez, nunca tenha realmente caracterizado a família brasileira, mas que continua sendo idealizada e, na sua ausência, é associada à presença de problemas no processo de escolarização (Salvari \& Dias, 2006; Souza, 2007).

Outro motivo atribuído remete ao professor: "os professores, às vezes, estão desestimulados" (assistente de direção); "pode ser que essa criança pegou algum professor ruim no decorrer e vai ficando uma defasagem enorme" (professor). Observa-se que os profissionais percebem que também os professores têm um papel nessa "defasagem", ou seja, vinculam a prática docente e a própria rotatividade de professores à presença de queixas escolares. Elas destacam a participação do professor no processo de produção da queixa escolar. Ainda assim, por se tratar de um fenômeno multifacetado, é necessário cuidado para não se atribuir "culpa" isoladamente ao professor.

Observou-se, nos relatos, ainda, a atribuição de motivos ao próprio aprendiz. A profissional da direção comentou sobre a "falta de interesse" e a necessidade de que o estudante "'acorde', que tenha vontade". Já a ATP fez relação desse fato com "alguma coisa [ocorrida] durante a infância deles", em que "não conseguiram assimilar aquilo ali"; enquanto o professor considerou que esse embaraço no processo de aprendizagem "pode ser genético, têm os déficits, o TDAH, todas essas coisas hoje aí". Essas análises podem ser relacionadas ao que Souza (2007) afirma, quando conclui que as razões para o fracasso escolar, historicamente, se voltavam de modo exclusivo para as capacidades e os "processos internos" do estudante (Souza, 2007).

Apesar dos questionamentos dos profissionais acerca do papel do professor e do próprio contexto em que o estudante está inserido, a atribuição de responsabilidade à família ou ao aprendiz é enfatizada com maior frequência. A análise de Asbahr e Lopes (2006, p.62) traz um questionamento acerca desses discursos, afirmando que, "ao se utilizarem dessa lógica para entender os problemas de aprendizagem, os professores tiram da sua alçada a responsabilidade pelo processo de escolarização das crianças e conclamam o saber médico a intervir nas questões educacionais".

Diante da discussão dos motivos da queixa escolar, algo parece comum a todas as falas trazidas: a atribuição de uma culpa, de uma responsabilidade, por vezes, externa ao ambiente escolar, mas sempre relacionada ao próprio indivíduo. Dessa forma, as justificativas para os problemas no processo de escolarização estiveram centradas, assim como na pesquisa de Bray e Leonardo (2011), no indivíduo, isto é, no estudante, na família ou no professor.

Sobre as estratégias utilizadas para o atendimento a casos de queixa escolar, a assistente de direção afirmou que os professores "costumam resolver na sala de aula, na medida do possível. Um caso ou outro, chamam a orientação para auxiliar, né? Chamam os pais para conversar". A ATP, em seu depoimento, comentou que a estratégia "cada professor tem uma forma de trabalhar. Tenho professores que não tiram alunos de sala de jeito nenhum... tenho professores que o aluno deu um espirro na sala e riu depois e ele tira o aluno da sala". E complementou, dizendo que "o aluno 
com dificuldade de aprendizagem, em sala de aula, ele acaba sendo tratado como os demais". Esse comentário da ATP, ainda que considerado uma crítica ao que é realizado, ou ao que não é realizado, revela a inclusão reduzida desses estudantes na escola, sem garantir o acesso à aprendizagem.

Outro trecho da fala dessa profissional chama a atenção: "quando [o professor] consegue estabelecer uma relação respeitosa com a turma, ele dificilmente vai ter problema com comportamento de aluno. Agora, o professor que chega na sala e quer fazer todo mundo ficar sentado no grito, ele vai perdendo o controle". Sobre esse aspecto, Tassoni (2006), em suas análises, argumenta que não há incompatibilidade entre aspectos de hierarquia e autoridade, inerentes ao papel do professor, com o vínculo afetivo, incluindo atitudes de compreensão, respeito e reciprocidade com vistas a realização de todos os envolvidos. Pode-se pensar que a lógica do professor de "ganhar no grito" não é condizente com uma atitude afetiva e, por consequência, são grandes as chances de não favorecer o aprendizado.

Ainda sobre esse eixo, um relato do professor chamou a atenção quanto às estratégias para o atendimento a casos de queixa escolar:

Vou pesquisar maneiras mais fáceis de tentar com que ele entenda. Eu vou lá, faço uma pesquisa com o aluno, pergunto do que ele gosta, trabalho com isso e, quando possível, em cima do cotidiano dele, contextualizando ele... Eu saio para fora da porta, eu encosto a porta e converso com ele: "ó, o que foi? Qual é o problema? É comigo, é alguma coisa pessoal? Eu sou teu professor, estou aqui para te ensinar, isso não está correto, nem está dentro da pauta da escola e também não é correto. Daí tu ficar me xingando, em nenhum momento eu faltei com educação contigo, como é que vai? Eu não gosto, não tolero isso.

Nessa fala, percebe-se uma busca de que os conteúdos façam sentido ao estudante, o que poderia funcionar como um facilitador do aprendizado. Logo na sequência, porém, o professor parece adotar o que pode ser considerado uma forma de "coação" ao estudante em casos de "problemas de comportamento", quando ele acaba impondo sua autoridade ao utilizar de um argumento de ordem moral. Esse tipo de procedimento pode colaborar para afastar o estudante e, por conseqüência, gerar um dificultador do aprendizado, visto que,por meio da cumplicidade, poderia ser gerado um aprendizado significativo (Codo \& Gazzotti, 2002 citado por Mattos, 2012).

Quanto aos procedimentos da escola para o atendimento a casos de queixa escolar, a assistente de direção afirmou: "tu não podes pegar o aluno e tirar ele de sala, tu não podes pegar um aluno e suspender". E comentou, ainda, que, "se o aluno apresenta alguma dificuldade de aprendizagem, eles [os professores] mandam para a equipe multidisciplinar, encaminham para lá". Já a ATP afirmou que a escola possui atendimento educacional especializado, com uma sala multifuncional, onde os estudantes com dificuldades de aprendizagem têm atendimento no contraturno escolar.
É possível perceber, nessas falas, que os procedimentos são fundamentados basicamente em uma visão individualista que naturaliza o fenômeno das queixas escolares e, ao considerá-las como pertencentes ao estudante, adota uma perspectiva reducionista, sendo que a ele caberia se "curar" de uma suposta dificuldade de aprendizagem (Souza, 2013). Dessa forma, ao focalizar as soluções para o problema somente em elementos como a avaliação, o encaminhamento e o reforço escolar, com ações centradas unicamente no estudante, ignoram-se, por vezes, a "natureza dialética" e o papel das mediações para qualquer aprendizado humano (Rego, 1997).

\section{Escola 3}

A escola 3 também faz parte da rede municipal de ensino fundamental do município e conta com cerca de mil estudantes.A respeito dos motivos atribuídos para a queixa escolar, dois entrevistados a atribuíram à família, em falas como: "a maioria é de família que não tem uma estrutura" (professora); "os alunos têm que levar para casa uma outra cultura" e que "o pai, quando chega em casa, já fica tão cansado que ele não quer ter conversa com o filho, quanto mais olhar o caderno" (ATP). Ainda que essa profissional tenha remetido a temática a uma discussão de ordem mais complexa, como a jornada de trabalho dos pais, ela também trouxe explicações voltadas para a ausência destes na vida escolar de seus filhos.

O diretor, contrariando a fala dos demais profissionais, ressaltou que não é possível ao professor oferecer um atendimento individualizado devido a todos os estudantes: "se o professor for atender aquelas dificuldades individuais, o resto do grupo não vai. Infelizmente, a escola trabalha para quem consegue, porque quem não consegue está ficando para trás". Esse é um exemplo do que pode ser chamado de inclusão excludente, ou seja, os estudantes estão apenas incluídos nas salas de aula, já que as práticas garantem unicamente sua entrada na escola, mas não lhes asseguram a permanência, nem o efetivo acesso ao conhecimento (Souza, 2013).

O diretor afirmou que a escola "não representa nada daquilo que o adolescente quer. A escola hoje está muito distante, muito atrasada em relação às expectativas do aluno. Isso acaba gerando essa falta de compromisso". A fala do diretor remete à questão da escola como um contexto desinteressante, sendo que a falta de compromisso dos estudantes, por vezes, está relacionada ao próprio contexto escolar. Esse posicionamento do diretor possui aproximações com discussões trazidas por Souza (2013) e Patto (1990), que expõem o papel da escola na produção do fracasso escolar. Nessa direção, ele questionou:

Por que o cara, dentro da sala de aula, para aquilo que o professor propõe ele não funciona, e para a vida social, na roda com os amigos, ele funciona de maneira perfeita, por que isso? Então, isso nos leva a acreditar que o problema 
não está com o aluno, mas sim, pela falta de compromisso que ele tem com a escola. E, por que essa falta de compromisso? Porque a escola não atende as ansiedades da criança, não atende aquilo que ele deseja, que ele almeja.

Com base em estudos realizados, pode-se pensar em alguns pontos interessantes visando responder a esta questão: "Por que essa falta de compromisso?". Souza (2014) ressalta a padronização e a busca da homogeneidade nas escolas, com aulas e lições iguais para todos na classe,além de ritmos e temas de estudo hegemônicos. Com isso, não é de se surpreender que, considerando que a escola é constituída por estudantes e seres humanos heterogêneos, as práticas de ensino não deem conta das ansiedades e dos desejos das crianças, visto que os próprios métodos e conteúdos, por vezes, não trazem sentidos positivos para os estudantes.

Quanto às estratégias para o atendimento a casos de queixa escolar, a ATP ressaltou a quantidade de estudantes em sala: "com pouco aluno em sala de aula, quem sabe o professor conseguiria mudar ou ter duas metodologias de ensino, mas, com a sala lotada, não tem como". De outro modo, o diretor observou que "o professor, na tentativa de trabalhar, tira da sala aquele que atrapalha. Esse é o procedimento". Esse relato destaca um procedimento costumeiramente utilizado,quando se entende que a solução para o impasse dos estudantes, considerados como "problemas", seria retirá-los de sala. E ressaltou ainda que, apesar de ter certo conhecimento das dificuldades, não vislumbra possibilidades de mudança:

Acho que hoje o professor não tem muito o que fazer para trabalhar as dificuldades. Ele claro que tem $N$ outras possibilidades de propor o trabalho, mas eu penso que qualquer proposta que seja feita, por qualquer que for $o$ professor, o aluno tem que querer $O$ aluno tem que querer, mas, infelizmente, o professor hoje, ele já está bastante desmotivado; ele não está propondo muita coisa. O professor vem, trabalha, dá sua aula; o aluno diz que não entende, ele volta a repetir. Mas ele não propõe algo novo. Infelizmente, eu percebo assim. Existem outras possibilidades? Existem, existem sim.

Ao retirar o estudante da sala, por exemplo, ou ao não buscar estratégias diferentes de ensino, a escola deixa de cumprir o seu papel, o qual, segundo Bray e Leonardo (2011), é o de ensinar visando o desenvolvimento e a formação crítica do estudante, para que este seja capaz de interpretar o mundo e agir sobre ele. Todavia, a fala dos profissionais leva a entender que a escola, por vezes, vem negligenciando sua condição de promotora de aprendizagem e desenvolvimento humano e não tem promovido transformações, ao contrário, vem reproduzindo a ordem social vigente.

Em relação aos procedimentos da escola para o atendimento de estudantes com queixa escolar, há um ponto convergente entre as falas da ATP e do diretor sobre chamar os pais em casos de problemas de indisciplina após uma advertência ao estudante. O diretor asseverou: "alguns alunos que têm dificuldades, é chamada a família, deixando claro para a família que esse aluno precisa de outro acompanhamento, daí a escola acaba oferecendo apoio pedagógico e também a orientação feita à família e feita ao aluno". Destacou, ainda, o diretor,que ocorre também encaminhamento para o Conselho Tutelar, ainda que isso aconteça como "pedido de socorro" em casos em que "a escola não sabe mais o que vai fazer".

Um método adotado pela ATP é o uso de um caderno que fica na coordenação da escola, no qual consta uma ficha onde é registrado "tudo que o aluno faz de errado segundo a visão do professor de sala". Ressaltou a ATP que essa visão do "errado" é do próprio professor, sendo que o papel dela é "consertar aquilo que está um pouquinho torto". Por sua vez, a professora destacou, quanto aos procedimentos, somente o acompanhamento a problemas de aprendizagem, em que há o serviço do reforço escolar, cujo procedimento, segundo ela, consiste em que "avaliar a turma em geral e ver quais alunos que tinham essa dificuldade de aprendizagem; eles foram para uma lista com o pessoal da supervisão junto com o pessoal da coordenação".

Observando-se essas estratégias, chama a atenção que todas elas estão centradas nos estudantes, colocando-os como supostos responsáveis pelos problemas de comportamento ou dificuldades de aprendizagem que apresentam. Seja na advertência, na suspensão, no caderno de anotações ou nos encaminhamentos, a lógica é de responsabilização do estudante, praticamente eximindo a escola do processo. Esses dados confirmam os encontrados por Bray e Leonardo (2006), segundo os quais as explicações para os problemas de comportamento centraram-se, igualmente, nos estudantes. Por vezes, não se apresenta uma visão dialética de processo que transcenda a noção de causalidade atribuída à produção de queixas escolares.

\section{Considerações Finais}

Os resultados apontaram o que a literatura há muito tem denunciado: os profissionais continuam a atribuir aos próprios estudantes e a suas famílias a responsabilidade pelas queixas escolares. Os procedimentos de atendimento aos estudantes com queixa escolar acabam por ser fundamentados em uma visão que naturaliza práticas e saberes relacionados ao fenômeno das queixas. A lógica implícita considera as queixas como próprias ao estudante, sendo que a ele caberia se "curar" dos problemas no processo de escolarização. Ao focalizar as estratégias em elementos, como a avaliação, o reforço e os "cadernos de anotações", reafirma-se o olhar para a queixa localizada no estudante. À escola caberia fazê-lo aprender, contudo sem rever o processo de produção dessas queixas no contexto escolar.

Nos dados apresentados, são comuns os discursos monocausais quanto ao fenômeno estudado, por vezes, 
sem considerar a "natureza dialética" e o papel das mediações no contexto escolar. Apesar de este estudo retratar um fenômeno multifacetado, o posicionamento dos profissionais participantes parece continuar legitimando exclusões e processos de naturalização de práticas e saberes, que acabam por estigmatizar crianças.

Em alguns relatos, foi apresentada uma visão idealizada de "família estruturada", apontado que a sua ausência seria responsável pelos problemas de escolarização. Persiste uma lógica culpabilizadora de que os estudantes não aprendem porque a estrutura da família não seria favorável ao bom desempenho destes na escola, assim desconsiderando "novos" modelos de família, não associados, necessariamente, à ausência de uma estrutura, mas, sim, à quebra de um modelo familiar idealizado ao longo da história.

Alguns discursos dos profissionais promovem uma discussão crítica sobre a existência de queixas escolares. Quando falas identificaram que a escola tem se apresentado desinteressante e que as estratégias de ensino utilizadas não têm sido adequadas às expectativas dos estudantes, é evidente que existem profissionais implicados em fazer ou pensar diferente, mas, por vezes, acabam se frustrando diante de um contexto escolar praticamente preditor de fracasso para o próprio professor, inclusive. Com turmas superlotadas, remuneração incompatível com a função, condições de trabalho inadequadas, tem-se uma realidade profissional desfavorável ao fazer docente.

Durante a coleta dos depoimentos, percebeu-se que os profissionais tinham menos compreensão do significado de queixa ou fracasso escolar, recorrendo aos termos mais conhecidos, como, por exemplo, dificuldades de aprendizagem e problemas de comportamento, ainda que estes não se refiram exatamente à completude do fenômeno.

A queixa e o fracasso escolar, apesar de debatidos há algumas décadas na psicologia escolar, parecem distanciados da formação ou dos estudos realizados pelos professores, demonstrando, nesse sentido, a relevância da discussão na formação dos profissionais. Os dados colhidos podem servir, ainda, para reforçar a importância e a necessidade da presença de psicólogos(as) nas escolas, acenando para a premência de uma atuação/intervenção crítica nos estabelecimentos escolares.

Por fim, todos os elementos apontados ressaltam a importância do estudo realizado e a necessidade de aprofundamento desta temática em outras pesquisas, envolvendo o entendimento dos estudantes e de suas famílias quanto à queixa e ao fracasso escolar, garantindo, assim, a ampliação de saberes na complexidade que o fenômeno demanda.

\section{Referências}

Asbahr, F. S. F.; Lopes, J. S. (2006). "A culpa é sua”. Psicologia USP, 17(1), 53-73.

Asbahr, F. S. F.; Martins, E.; Mazzolini, B. P. M. (2011). Psicologia, formação de psicólogos e a escola: desafios contemporâneos. Psicologia em estudo, 16(1), 157-163.

Asbahr, F. S. F.; Nascimento, C. P. (2013). Criança não é manga, não amadurece: conceito de maturação na teoria históricocultural. Psicologia ciência e profissão, 33(2), 414-427.

Bray, C. T.; Leonardo, N. S. T. (2011). As queixas escolares na compreensão de educadoras de escolas públicas e privadas. Psicologia Escolar Educacional, 15(2), 251-261.

Chizzotti, A. (2001). Pesquisa em ciências humanas e sociais. São Paulo: Cortez.

Gil, A. C. (2002). Como elaborar projetos de pesquisa. São Paulo: Atlas.

Godoy, A. S. (1995). Pesquisa qualitativa: tipos fundamentais. Revista de Administração de Empresas, 35(3), 20-29.

Mattos, S. M. N. (2012). Inclusão/exclusão escolar e afetividade: repensando o fracasso escolar das crianças de classes populares. Educação em revista, (44), 217-233.

Moysés, M. A. A. (1990). Fracasso escolar: uma questão médica? Série Ideias, (6), 29-31.

Moysés, M. A. A.; Collares, C. A. L. (1997). Desnutrição, Fracasso Escolar e Merenda. In: Patto, M. H. S. (Org.), Introdução à psicologia escolar (pp. 225-256). São Paulo: Casa do Psicólogo.

Oliveira, J. L. A. P.; Bragagnolo, R. I.; Souza, S. V. (2014). Proposições metodológicas na intervenção com estudantes com queixa escolar. Psicologia Escolar e Educacional, 18(3), 477-484.

Patto, M. H. S. (1990). A produção do fracasso escolar. histórias de submissão e rebeldia. São Paulo: T.A. Queiroz.

Rodrigues, M. C.; Campos, A. P.; Fernandes, I. A. (2012). Caracterização da queixa escolar no Centro de Psicologia Aplicada da Universidade Federal de Juiz de Fora. Estudos de Psicologia (Campinas), 29(2), 241-252.

Rego, T. C. (1997). Vygotsky: uma perspectiva histórico-cultural da educação. Petrópolis: Vozes.

Rosenthal, R.; Jacobson, L. (1981). Profecias autorrealizadoras em sala de aula: as expectativas de professores como determinantes não intencionais da competência intelectual. In: Patto, M. H. S. (Org.).Introdução à Psicologia Escolar(pp. 258-295). São Paulo: T.A. Queiroz.

Salvari, L. F. C.; Dias, C. M. S. B. (2006). Os problemas de aprendizagem e o papel da família: uma análise a partir da clínica. Estudos de Psicologia (Campinas), 23(3), 251-259.

Souza, B. P. (2007). Orientação à queixa escolar. São Paulo: Casa do Psicólogo. 
Souza, M. P. R. (2000). Formação de psicólogos para o atendimento a problemas de aprendizagem. Estilos da clínica, 5(9), 134-154.

Souza, M. P. (2009). Psicologia Escolar e Educacional em busca de novas perspectivas. Psicologia Escolar e Educacional, 13(1), 179182.

Souza, S. V. (2013). O estudante (in)visível na queixa escolar visível: um estudo sobre a constituição do sujeito na trajetória escolar. Tese de Doutorado, Universidade Federal de Santa Catarina, Florianópolis-SC.
Souza, B. de P. (2014). Puxando o tapete da medicalização do ensino: uma outra educação é possível. Nuances: estudos sobre educação, 25(1), 299-316.

Tassoni, E. C. M. (2006). Dimensões afetivas na relação professoraluno. In: Leite, S. A. S. (Orgs.), Afetividade e Práticas Pedagógicas (pp. 47-96). São Paulo: Casa do Psicólogo.

Yin, R. K. (2001). Estudo de Caso: planejamento e métodos. Porto Alegre: Bookman.

Recebido: 4 de setembro de 2017

Aceito: 27 de setembro de 2018 